\title{
E-Government Readiness Assessment for Government Organizations in Developing Countries
}

\author{
Ibrahim A. Alghamdi (Corresponding author) \\ School of Computer Science, Engineering and Mathematics, Flinders University \\ GPO Box 2100, Adelaide SA 5042, Australia \\ Tel: 61-41-308-9963Ｅ-mail: Algh0044@flinders.edu.au
}

Robert Goodwin

School of Computer Science, Engineering and Mathematics, Flinders University

GPO Box 2100, Adelaide SA 5042, Australia

Tel: 61-8-8201-3113 E-mail: robert.goodwin@flinders.edu.au

Giselle Rampersad

School of Computer Science, Engineering and Mathematics, Flinders University

GPO Box 2100, Adelaide SA 5042, Australia

Tel: 61-8-8201-5746 E-mail: giselle.rampersad@flinders.edu.au

Received: February 27, 2011

Accepted: March 14, 2011

doi:10.5539/cis.v4n3p3

\begin{abstract}
ICT has become an increasingly important factor in the development process of nations. Major barriers can be met in the adoption and diffusion of e-government services depending on the readiness of a country in terms of ICT infrastructure and deployment. This study aims to define organizational requirements that will be necessary for the adoption of e-government to resolve the delay of ICT readiness in public sector organizations in developing countries. Thus, this study contributes an integrated e-government framework for assessing the ICT readiness of government agencies. Unlike the existing e-government literature that focuses predominantly on technical issues and relies on generic e-readiness tools, this study contributes a comprehensive understanding of the main factors in the assessment of e-government organizational ICT readiness. The proposed e-government framework comprises seven dimensions of ICT readiness assessment for government organizations including e-government organizational ICT strategy, user access, e-government program, ICT architecture, business process and information systems, ICT infrastructure, and human resource. This study is critical to management in assessing organizational ICT readiness to improve the effectiveness of e-government initiatives.
\end{abstract}

Keywords: E-government, Organizational adoption, Organizational ICT strategy, E-readiness

\section{Introduction}

Electronic government (e-government) refers to the use of information and communications technology (ICT), and specifically the Internet, as a tool to achieve better government (OECD, 2003). ICTs have been introduced in the government sector in the past two decades in an attempt to achieve greater operational efficiency and effectiveness (O’Neill, 2009).

E-government has several dimensions. Every dimension requires leadership, cross-coordination and knowledge, all integrated with an ICT strategy to achieve the vision (Bakry, 2004, Caldow, 1991). The availability of an e-government framework for assessing the ICT readiness in public sectors is critical in developing effective e-government policies and strategies (ACM, 2008). While there are many e-readiness assessment tools, there is a need for fixed guidelines on how these tools can be shaped as frameworks in implementing assessment in particular e-government contexts (ACM, 2008). The design of e-government readiness assessment frameworks requires comprehensible measurement of the assessment design that determines factors clearly derived from information needs (ACM, 2008, APEC, 2008, CID, 2002). 
This study provides an integrated framework for assessing organizational ICT readiness of e-government that integrates pertinent components in a developing country public sector. The framework assesses e-government organizational ICT readiness through seven dimensions: user access, e-government program, ICT architecture, business process and information systems, ICT infrastructure and human resources, and e-government strategy which influences the other factors. E-readiness is the aptitude of an economy to be a participant in the digital economy (Bui et al., 2003).

\section{Theoretical Background}

During the last two decades, the e-government stream of research within the information systems literature has grown significantly (Andersen and Henriksen, 2005, Heeks, 2003, Thompson and Jones, 2008). Some authors have investigated the potential impacts of ICT and management issues (Bellamy and Taylor, 1994, Fountain, 2001, O'Neill, 2009). Others have focused on ICT transfer, culture and country-specific factors in e-government development, and diffusion among stakeholders in developing countries (Abdalla, 2006, Alshihi, 2005, Baark and Heeks, 1999, Rahman, 2007).

More research is needed on organizational issues impacting on e-government effectiveness. The literature has a predominant focus on technological issues such as ICT architecture and infrastructure such as portals, security and authentication, web standards (Moon, 2002); interoperability (Millard, 2007); metadata, open source software, domain policy, connectivity (Reddick, 2005); procurement practices, project design (Gil-Garcia and Pardo, 2005, Martin and Bryne, 2003); and implementation issues (Heeks, 2005a, Layne and Lee, 2001, O'Neill, 2009). Extant research predominantly focuses on issues of functionality (Layne and Lee, 2001, Millard, 2007) and the technical aspects (Chen, 2002, Safai-Amin, 2002) of ICT in an e-service delivery context. However, there is a considerable gap between what can be done by using ICTs and what has been achieved in reality (OECD, 2002, OECD, 2003). E-government initiatives are frequently unsuccessful because of one of the following: the technical system is never implemented; the technology is discarded after implementation; key goals are not achieved (relating to cost, implementation timeframes, and capability) and/or they result in considerable unpredicted outcomes (Heeks, 2005b). While some studies focus on the success and failure rates of e-government, more than one-third of e-government initiatives are overall failures (e.g. the failure of decision support systems in East Africa); an additional, half can be viewed as limited failures (e.g. the limited or partial failure of management information systems in Eastern Europe); and approximately one seventh are successes (Heeks, 2003).

The existing e-readiness tools fail to adequately address organizational issues. For instance information access within organizations is often overlooked (Stephen et al., 2006). Measures of physical ICT infrastructure and education are popular factors in e-readiness assessments tools. Extant tools provided unsuitable parameters and factors in assessing the comprehensive e-readiness of organizations and were matched by policy and economic environment surroundings (Rizk, 2004). Stephen et al. (2006) suggest that a new e-readiness integrated tool is needed that highlights information access and also co-locates the different segments of organizational, ICT, human resources, and external readiness.

In addition to ignoring organizational issues, existing tools do not place sufficient emphasis on e-government considerations. Studies of e-government framework assessment point out that some e-readiness tools do not comprise e-government in their assessments (Azab et al., 2009). These tools mainly evaluate e-services and accessibility, support and usage of ICT (Azab et al., 2009). E-readiness assessment tools are inadequate in considering factors relating to e-government, such as culture and technology acceptance of public officials (Alshihi, 2005), excellence of ICT infrastructure in government organizations, strategies, national e-government program architecture. There is insufficient research linking e-readiness and e-government implementation in a nation (Altman, 2002). A concentration on the mainly specific issues to e-government when endeavouring to measure it is highly recommended (Jansen, 2005).

Research pertaining to organizational ICT readiness for e-government is embryonic. While the literature recognizes the significance of ICT readiness in organizations (Andersen and Henriksen, 2005), empirical work remains limited. E-government literature focuses on technical capabilities and relations and their consequences on e-services (Andersen and Henriksen, 2005, Norris and Lloyd, 2006). However, e-government literature largely ignores e-government organisational strategy, and national e-government program model connected to relative factors. Since e-government is a relatively new research area, organizational ICT architecture and adoption strategy have not been widely discussed in the literature. Some studies have discussed the dimensions of e-government, such as Ebrahim and Irani (2005), Heeks (2003), and Richard (2001). However, these studies did not concentrate on the component of e-government organizational strategy and national e-government 
program model and its relationship to the ICT readiness, organizational architecture, business process and Information systems, ICT infrastructure and human resource dimensions. Research is necessary that provides an integrated architecture framework for e-government adoption that can assist ICT managers in assessing the ICT readiness for an organization in public sector.

\section{A Suggested E-Readiness Framework for Assessing Government Organizations}

The proposed framework stems from previous research on information systems e-government success, and e-readiness. As illustrated in Figure 1, it integrates seven dimensions of e-government organizations. First, it explains organizational ICT strategy as a major factor in reaching a successful e-government adoption in Section 3.1. Section 3.2 clarifies the high demand for e-service delivery channels in the public sector. Section 3.3 describes the three major components of the e-government program which should be connected to the government agencies. Section 3.4 explains ICT architecture roles to advance the success of e-government organization portals. Section 3.5 focuses on business processes, knowledge management, change management, and ICT applications. Section 3.6 describes technologies that should be prepared before e-services can be offered consistently and efficiently to the citizens. Finally, Section 3.7 explains the important factors of human resources in the success of e-government.

\subsection{E-Government Organizational ICT Strategy}

E-government strategy is "is essential for effective e-government implementation. A strategic plan provides a roadmap for an organization to move from its current state to its desired medium or long term future state" (Lee, $2010 \mathrm{pp}$ 7). A lack of consensus exists within the literature about the importance of strategy for e-government adoption. Some studies on e-readiness assessment tools stress that ICT strategy is fundamental for e-government adoption to be succeed (APEC, 2000, APEC, 2008, Bakry, 2004) studies reveal that IT strategy does not have a strong impact on e-government readiness (Azab et al., 2009). However, these studies and e-readiness assessment tools consider the strategy as a national e-government strategy not as a government organizational ICT strategy.

The ICT-related Millennium Development Goals (MDGs) incorporate e-readiness considerations (World Bank, 2005). The MDGs highlight important issues for e-readiness assessment (World Bank, 2005). These assessments can be utilized to assist countries in achieving e-government readiness including strategy. E-government strategy should identify a number of visions and goals to validate its cost and to verify the degree to which these are accomplished (World Bank, 2005). Strategy should identify possible challenges, technological, economic, and political (World Bank, 2005). An e-government strategy should be aligned with the organization's business and information systems strategy. Also, e-government strategy should be compatible with the strategy of e-government national program (Yesser, 2005). In addition, both Azab et al.(2009) and Bakry(2004) develop a framework for e-readiness assessment model. One of their categories is a strategy. The strategy construct in both models includes leadership and action plans. Strategy should apply an action plan that includes: organization (accountability, structure, resource allocation, IT policies and procedures) (Azab et al., 2009). It offers the suitable strategy to assist all programs in a aligning the goal, framework, capacity, and risks identified by the whole organization.

This model should be applied in developing nations involved in the process of developing ICT visions and plans to move their countries forward in the digital age. The model would be valuable to ICT program directions, ICT policy developers, and e-government professionals seeking to assess the level of ICT readiness to ensure the success of organizational e-government plans.

Moreover, transformation and action plans should consider funding sources, and recognize various e-government stakeholders in order to verify their responsibilities and the significance to be achieved (Azab et al., 2009).

If applied effectively in developing countries, strategy can advance e-government productivity in the public sector. We propose that strategy can influence e-government organizational ICT readiness drivers including e-government user access, e-government program, business processes and information systems, ICT infrastructure, and human resources. Each of the mentioned dimensions is described in the following sections below.

\subsection{E-government User Access}

An access channel is "a means for users to contact public administrations (inbound) or for public administrations to contact their users (outbound) with the aim of acquiring or delivering public services" (IDA, 2004 pp 4).

ICT has emerged as an intermediary in assisting successful communication between stakeholders (Abdalla, 2006). While extant research predominantly focuses on functionality factors and e-services delivery prospect 
(Becker and Nowak, 2003, Carter and Belanger, 2005), little attention has been placed on factors such as usability, accessibility and the availability of public e-services from an e-government user's perspective (Alsobhi et al., 2009). E-government needs to be driven by user demand, not only by cost reduction goals. These user requirements includes time savings, increased convenience and accessibility (World Bank, 2005, Yesser, 2005), has been affected by the need to provide e-government users with more extensive and effective channels for interacting with government using web-based systems (Brannen, 2001). Service delivery refers to the process of providing government services through e-government portals (Maheshwari et al., 2009). Moreover, accessibility refers to the ease of attaining information and services offered through an e-government portal (Criado and Ramilo, 2003).

Access channels are important for e-government and refer to the means by which users can obtain different government services (Ebrahim and Irani, 2005). Users can be citizens, employees, government sector, private sector, and other groups or communities (Ebrahim and Irani, 2005). Access channels comprise online and offline channels of delivery through which products, services and information are utilized, accessed and communicated by various technologies such as Internet, ATMs, PCs, fixed-line and mobile phones (WAP), and kiosks in public places (Ebrahim and Irani, 2005, IDA, 2004).

\subsection{E-government Program}

\subsubsection{Definition of E-government Program}

This dimension is regarding integrating digital data of different organizations into a single-sign on of e-government website portal. E-government program intends to deliver interoperability and integration of services among all government organizations (G2G), between government organizations and customers (G2C), between government organizations and business organization (G2B), and between government organizations and their employees (G2E) (Yesser, 2005).

E-government program attempts to accomplish superior efficiency in government performance, in the course of raising the performance of services and transactions for users from various sectors of society with ease and professionalism (Almarabeh and Abuali, 2010). E-services could include services such as rate paying, licensing or information queries (Almarabeh and Abuali, 2010). Experts describe the portal as "a service transformation program" because it serves as an umbrella for all government departments, authorities and administrations. The e-government program can lead to increased government efficiency and effectiveness in delivering suitable services to various sectors of customers through multiple delivery channels (AlMansoori, 2010). The national e-government program can be designed to achieve objectives including raising the public sector's productivity and efficiency; providing better and more easy-to-use services for individual and business customers; increasing return on investment (ROI); and providing the required information in a timely and highly accurate fashion (OECD, 2003, Yesser, 2005).

There are three levels of e-government portal complication which are information distributing and linking of existing web sites, single organization transactions, and transactions involving integration of multiple organizations (IBM, 2001). From a portal management viewpoint, it is essential to offer stable and Single-Sign On (SSO) interface to ease and enlarge user access and control, for instance using authorized e-services, search capabilities, and instant messaging. In addition, having compatible systems for linking affective tool such as Government Service Bus (GSB) which should be available on e-government portal to register, dynamically identify and categorize users/organizations, and providing the organization the ability to access specific applications and information to meet the particular requirements of organization. Security is another key element of this dimension, through connecting to a secure network such as Government Secure Network (GSN) which should be available as well by e-government portal, the organizations will achieve protected transactions. The framework proposed in this study comprises three factors to help in assessing the organizational portal readiness that linked to the e-government national portal, from which: SSO, GSB, and GSN more details provided in the three below sections.

\subsubsection{Single-Sign-on Portal (SSO)}

A website portal is a multi-functional information systems which provides a single point of access to relevant services via the Web-enabled interface (Forman and Thompson, 2007). The SSO portal enables login to multi-portals and applications (Microsoft, 2010). Accounts created in one portal can be shared and used to login to other portals (Microsoft, 2010). Users will not need to remember multiple accounts to access different portals or applications (Microsoft, 2010). Most governments in developed and developing countries have established web portals to offer electronic service delivery to their citizens (Chen, 2002, Lee et al., 2005). 
Portals are single-point web browser interfaces applied to encourage the collection, exchange and diffusion of information (Lee, 2010). Moreover, a national portal, along with other regional portals, establishes an interface between citizens, government departments, businesses, and employees. Organizations should develop SSO portals that require knowledge of specific organizations to result in efficient e-government projects, and to lead to effective integration of different governmental agencies (Sharifi and Zarei, 2004).

\subsubsection{Government Service Bus (GSB)}

Government Service Bus (GSB) should be the middle platform of integration and services for government e-services and transactions, and should offer frequent services such as identity management, e-Payment and core data exchange through e-government national portal (Yesser, 2005). The new generation of integration called Enterprise Service Bus (ESB) launches ready-made integration codes using open standard, messaging, and freely joined Service Oriented Architecture (SOA) rules (Chappell, 2004). Organizations should apply the solution which required for as a quick win phase, enabling the provision of e-services from different governmental agencies to use a common infrastructure for integration, sharing of data and the use of centralized shared services through the GSB.

\subsubsection{Government Secure Network (GSN)}

The Government Secure Network (GSN) is important in providing a communications network specifically for electronic government transactions. Thus, it links government agencies to the e-Government Data Centre, which should be established at the highest technical specifications and security for use in hosting the gate of the national electronic services, and the host site for the e-government program (Yesser, 2005). The GSN facilitates the e-government program to becoming a key connection point among government organizations in a security and a cost effective manner. Organization communications should be characterized by a high degree of efficiency and reliability to provide very high transfer speeds and should provide security in the transfer of data through the use of the latest techniques of data transfer protocols to be able to connect to other agencies through GSN.

\subsection{ICT Architecture}

ICT architecture refers to the fundamental technological architecture of an e-government portal (Maheshwari et al., 2009). In ICT architecture, stability and scalability are critical for successfully implementing an e-government portal. A government organization's portal must be ready and capable to offer access to all government back-end services from delivery channels; to meet diverse back-office needs; to cater for varying levels of technology; to handle digital authorization; and to manage increased degrees of traffic (Accenture, 2004).

However, implementing e-government projects is problematic for many authorities because these projects frequently fail to advance e-service value and quality (Accenture, 2005). E-government portals allow governments to extend services to citizens, other government agencies, businesses and employees integrated as a single unit (Stauffacher, 2002). Despite high possible advantages, few e-government organizational portals can be considered as successful (Norris and Moon, 2005).

Technical architecture is an important technical indicator that refers to the technical structure and orientation. To implement e-enablement projects, several technical structure requirements are demanded; for software development, hardware structure and standards, services orientation and design. There are several factors to help in assessing the technical architecture readiness, from which: availability of portal, layered structure, and Service Oriented Architecture (SOA) as described in next sections (Oracle, 2010).

\subsubsection{Availability of Portal}

Availability refers to the types, levels, and number of services provided through an government public sector portal (Maheshwari et al., 2009). A portal can offer many services that are consistent with principles of customer centric portal design, for example services are triggered from portal using shared IT support services such as payment, security, DMS (Bretschneider et al., 2003). A (UNDPEPA/ASPA, 2002) study suggests that five types of services can be provided through e-government portals including emerging, enhanced, interactive, transactional, and integrated services. Portal availability is an essential aspect for e-government services. The portal existence effects readiness perception.

\subsubsection{Layered Structure}

Layered structures are commonly used in architectural design. They permit classification into vertical hierarchy and reduction of package combination (Maciaszek, 2004). 
Presentation Control Mediator Entity Foundation (PCMEF) aims to minimize dependency and object intercommunication (Maciaszek, 2004). PCMEF acquires stimulation from previous design patterns such as Data Mapper, MVC, Observer, Chain of Responsibility and Mediator (Maciaszek, 2004). PCMEF is a layered architectural framework which is comprised of four layers: presentation, control, domain and foundation (Maciaszek, 2004). These layers reflect the portal design, which can be assess the readiness of the portal performance through the: operating systems, communication standards used, and infrastructure accessibility.

\subsubsection{Service Oriented Architecture (SOA)}

A Service Oriented Architecture (SOA) approach to e-governance supports IT with service delivery objectives and allows different government agencies to reprocess developed assets (Behara G. et al., 2009, Oracle, 2010). It is useful to offer flexible SOA solutions as this can be beneficial for governing, integrating, deploying, securing, and managing services, irrespective of the platforms on which they were created (Behara G. et al., 2009, Oracle, 2010).

SOA diminishes the dependency on back-end applications and reduces the requirement to write code every time there is a change in policy because it can deal with different platforms, and can establish new software that advances the direct collaboration of e-government users irrespective of the delivery model (Behara G. et al., 2009, Oracle, 2010). Furthermore, internal and various external interfaces between applications and/or databases follow principles of service orientation (Oracle, 2010).

\subsection{Business Process and Information Systems}

Business process and information systems includes the collaborative meeting between the business management and ICT management to define, agree, and communicate the vision, goals, objectives, action, requirements, and governance in understanding the incorporated modification of the business through the ICT supported information systems (OECD, 2002).

However, the current e-readiness tools are inadequate in effectively addressing the issue of information access (Stephen et al., 2006). Therefore, the proposed framework focuses on four important factors of business process and information systems including Business Process Reengineering (BPR), knowledge management, change management, and ICT application in government organizations.

\subsubsection{Business Process Re-engineering (BPR)}

E-government services can play an important role in reforming government internal work processes to advance efficiency (Lee, 2010). In particular, improving government work processes using ICT leads to increased accuracy by providing integrated reporting systems of central and local governments. Furthermore, it also results in advanced efficiency by sharing information both within and between agencies. (Lee, 2010)

One of the important tools utilized in accomplishing business process innovation is Business Process Reengineering (BPR) (Lee, 2010). BPR includes redesigning the work flow within or between departments for enhancing process effectiveness and efficiency ((Sharifi and Zarei, 2004).

In addition, BPR in e-governance includes significant analysis and thorough re-engineering of workflows and processes in the organization (Behara G. et al., 2009). BPR can help in achieving a high level of process performance and service delivery for government employees and citizens (Behara G. et al., 2009). Moreover, a BPR project reduces barriers around the decision making process (Sharifi and Zarei, 2004).

\subsubsection{Knowledge Management}

The majority of e-government organisations implement knowledge management (KM) based predominantly on physical ICT infrastructure. Such behaviour may lead to inadequate short-term advantages as successful knowledge management depends on cultural changes and promoting an environment in which people are agreeable to share their experiences with others (Starkey.K. et al., 2004). KM is focused on improving knowledge, capabilities and skills; and achieving a change of attitude (Rampersad, 2002). Training improves the effectiveness of KM efforts as it communicates values and inspires appropriate work culture in the organisation (Rampersad, 2002).

\subsubsection{Change Management}

Change management has enjoyed a dramatic increase in interest directed toward organizational development related research: the net results being streams of research focusing on the learning organization, knowledge economics, and management, complexity theory and the 'virtual' organization (Balogun and Hailey, 2004). Demand for change management literature remains high as managers endeavour for that 'perfect' change as many continue to consider reported failure rates, as high as 70 per cent, rather excessive (Balogun and Hailey, 2004). 


\subsubsection{ICT Application in Government Organizations}

ICT applications refer to logical systems that manage the data objects in the data architecture and that support the business functions in the business architecture (Macasio, 2009a). ICT application offers a design for each application system to be implemented and deployed (Macasio, 2009a). This provides integration between application systems and the core business processes of the organization (Macasio, 2009a). ICT applications can be used to improve user's trust, knowledge sharing and information processing for interacting within and between organizations (Moodley, 2003). ICT applications integrate front-end e-government layer applications, for example online transaction interfaces in the government portal with back-end actions for instance, presented databases and data warehouses (Ebrahim and Irani, 2005).

E-government component has two categories: front-office and back-office (Lee, 2010). The front-office category involves online service delivery to citizens, businesses and employees, via the Internet or other multiple access channels (Lee, 2010). The back-office category contains internal government management and information sharing both within and between government agencies. Government-to-Citizens (G2C) and Government-to-Business (G2B) services are classified as front-office, and Government-to-Government (G2G) and Government-to-Employees (G2E) as back-office (Lee, 2010).

This article summarizes previous studies view of effective e-government delivery, this requires the following ICT applications as shows in Table 1.

In addition, after reviewing literature, ICT applications in government organizations can be classified into three categories:

- Common Applications used by all government organizations such as HR systems, financial systems, and ECM.

- Applications that are used by many government organizations such as recruitment applications.

- Applications that are used by one government organization such as a core business application.

3.6 ICT Infrastructure

The dimension of ICT infrastructure has been a key issue for many researchers. Several studies identify the organization's ICT infrastructure and focuses technology components (Bakry, 2004, Center for International Development - Harvard University and IBM, 2007). However, the ICT infrastructure concept is more complicated. In addition, ICT design relies on the service oriented architecture model implemented with web-services.

Having a successful e-government strategy that requires that government organizations establish a suitable IT infrastructure to support information systems and applications (IBM, 2001). Many developing countries suffer from implementing ICT projects, and are not able to install the suitable ICT infrastructure for e-government deployment. The digital divide between richer countries and developing ones is large with high-income economies (World Bank, 2006).

Based on previous studies, ICT infrastructure includes a group of shared, physical ICT resources that offer a foundation to facilitate existing and future business applications. These resources include: (1) hardware and software (e.g., operating systems); (2) connectivity; (3) security; and (4) operations.

\subsubsection{Hardware and Software}

E-government ICT infrastructure possibly will include some technologies with a network infrastructure at its origin; containing web servers, application servers, storage devices, PCs, printers, scanners, routers, switches, firewalls, hardware and operating systems, and data and application development tools (IBM, 2011, Macasio, 2009a). The storage, acquisition, and data exchange must be provided through these technologies in order to allow date access internally or externally to the organization. Moreover, these technologies particularly servers work through professional network technology and internet connectivity that advance communication and information transmission within and between organizations online (Ebrahim and Irani, 2005).

\subsubsection{Connectivity}

Connectivity offers necessary technologies, such as Local Area Network (LAN) and Wide Area Network (WAN). LANs "allow integration with current hardware resources such as PCs, laptops, and mobile phones straightforward and without complications which supporting the organization existing IT provision" (Ibrahim and Irani 2005 pp 599). Also, LANs support the provision of user-friendly and innovative online services involving the transmission of data of various formats such as text, graphics, audio and video ((Ebrahim and Irani, 2005). WAN is a communications network that makes use of existing technology to connect local computer networks into a larger working network that may cover both national and international locations (IBM, 2011, 
Macasio, 2009a). This is in contrast to LAN which provides communication within a restricted geographic area.

The aim of these technologies is to support and integrate the operations of business processes and information systems dimension across organizations by providing the necessary standards and protocols all the way through ICT network and communication infrastructure solutions such as the intranet, extranet, Internet, and VOIP.

\subsubsection{Security}

This dimension must integrate a high level of security solutions and technologies such as Public Key Infrastructure (PKI), firewall, biometrics, digital signature and certificate, and sophisticated encryption technique, which secure e-government interoperation, government electronic transactions, and delivery systems to guarantee protection and prevent fraud and other vulnerabilities at all levels of the government ICT infrastructure (Ebrahim and Irani, 2005).

One of the most important aspects of the security plan is its set of security objectives (Pfleeger and Pfleeger, 2003). There are five objectives of computer network security including (1) a security policy: an explicit and well-defined security policy imposed by the system is essential; (2) identification: the objects have to be individually identified: identification is essential so that objects access can be examined; (3) accountability: all tasks that influence the security system must maintain complete and secure records, for instance, actions include identifying new users to the system, assigning or updating the security level of elements, and denying access attempts; (4) assurance: the computing system must contain techniques that enforce security, and it must be able to assess these effectiveness of the techniques and (5) continuous protection: the techniques that implement security must be protected against unauthorized access or change (Pfleeger and Pfleeger, 2003).

\subsubsection{Operations}

The operations set of processes provides the day-to-day work needed to monitor and maintain a continuous ICT infrastructure and operating systems (Patrizio et al., 2004). They explain a number of the jobs associated with the processes are job scheduling, data management (including backup and recovery management), enterprise command centre, physical database administration and proactive hardware maintenance. Furthermore, the increased demand in recent years for continuous operation of applications and database in the presence of disasters (Garcia-Molina and Polyzois, 2002). Disaster Recovery (DR) solution is fundamental to ensure continuous operation through a remote backup of applications, database and communication, even in the incidence of widespread failures (Garcia-Molina and Polyzois, 2002).

\subsection{Human Resources}

The area of human resources focuses on the roles and responsibilities required to achieve the goals of the organization (Macasio, 2009b). Human resources are one of the most important factors in the success of e-government (Azab et al., 2009, Bakry, 2004). In addition, a number of constructs need to be considered such as user satisfaction, impact on employees, skills (adaptation to change, use of technology, integration, customer service) and HR training and development (Azab et al., 2009).

Technical support can play a significant role for supporting three issues (Patrizio et al., 2004). First, it assists with design and planning by given that technical assessments, both in the form of Proof of Concept (POC) and pilot tests of new technologies. Second, it helps the RFI (Request for Information) and RFP (Request for Price) processes. Technical Support takes actions as a relationship with dealers on technical issues. Third, it is responsible for creating and maintaining the technical library and the technical knowledge base for the organization.

Human resources factors which contributes towards an organisation's e-government goals include training and support system which maintains the currency of personnel skills sets in keeping with e-government developments; IT assistance; such as help desks; suitably qualified IT staff within the public organisations; IT governance; and technical e-government experience.

\section{Discussion}

The main aim of this paper is to provide an integrated framework for assessing organizational ICT readiness of e-government that represents the association of relative components in a developing country public. In deciding whether a government organization is ICT ready or not, e-government organizational strategy considerations are important to validate costs and to ensure the level to which visions and goals are accomplished; and to recognize possible challenges such as technological, and online policy. Ensuring compatibility with an e-government program, providing an action plan, and monitoring these goals via steering a committee are significant.

User access readiness includes the channels that government users can access the various government services. 
Government users can be citizens, other government departments, businesses, employees, and other community members. Measuring organization capability is fundamental to integrating digital data from different government organisations into a web-portal of government services through a one-stop e-government portal. Government web-portal should be assessed, because it is emerging as a key priority for public sector organizations, as they develop their e-government initiative and create electronic interaction between users. Assessing information systems are essential to re-engineer business processes, improve applications and systems, and provide adequate e-government services. ICT infrastructure readiness should be measured aligned with identified goals. Finally, the organization's technical capabilities should be checked to make a decision whether the existing ICT human resources are sufficient to accomplish the aims foreseen or not.

\section{Conclusion}

This article proposed an integrated framework for assessing ICT readiness of e-government organizations in developing countries. Unlike the previous e-government literature that focuses predominantly on technical issues and employs generic ICT readiness tools, this study contributes an organizational perspective for assessing ICT readiness that incorporates pertinent factors to an e-government context. The proposed e-government framework comprises seven dimensions of ICT readiness assessment for government organizations including e-government strategy, user access, e-government program, ICT architecture, business process and information systems, ICT infrastructure, and human resources.

This study offers useful implications to e-government decision makers, ICT mangers, ICT specialists and suppliers in the public sector by providing insights geared towards improving business decision-making, and expanding competitive advantage from effective e-government services. It equips key stakeholders with a framework that could be applied in performing regular assessment of e-government ICT readiness to identify limitations and provide suitable solutions. Agencies assigned responsibility for assessing ICT readiness may refer to this framework as a useful resource during the e-government project. The proposed framework for assessing e-government ICT readiness will decrease difficulty associated with ineffective e-government strategies in the public sector through understanding the important e-government dimensions highlighted in the proposed framework.

Overall, this study empowers ICT government organizations with a comprehensive resource pertaining to e-government organizational ICT readiness and provides a comprehensive assessment methodology to guide agencies self assessments.

While this framework is useful, more research is necessary. The conceptual framework offered in this study paves the way for future quantitative empirical research to test the framework. Nevertheless, this study is an important conceptual step in identifying relevant factors from an organizational perspective for assessing ICT readiness in an e-government context.

\section{References}

ABDALLA, K. A. (2006). Stakeholder Perceptions of Issues for Successful Information Technology Transfer in a Developing Country: A Case Study of the United Arab Emirates. A Research Proposal Submitted for Candidature for the Degree of Doctor of Philosophy, The University of Southern Queensland.

ACCENTURE. (2004). eGovernment Leadership: High Performance, Maximum Value. The Government Executive Series.

ACCENTURE (2005). Leadership in Customer Service: New Expectations, New Experiences. The Government Executive Series.

ACM. (2008). ACM International Workshop on Vehicular Ad Hoc Networks. Proceedings of the ... ACM International Workshop on VehiculAr Inter-NETworking. New York: ACM Press.

ALMANSOORI, R. (2010). Abu Dhabi e-Government Program [Online]. Available: http://www.abudhabi.ae/egovPoolPortal_WAR/ [Accessed 28 Sep 2010].

ALMARABEH, T. \& ABUALI, A. (2010). A General Framework for E-Government: Definition Maturity Challenges, Opportunities, and Success. European Journal of Scientific Research, 39 29-42.

ALSHIHI, H. (2005). Critical factors in the Adoption and Diffusion of e-government initiative in Oman. Fulfilment of the requirements of the Degree of Doctor of Philosophy in Business Information Systems Thsese, Victoria University. 
ALSOBHI, F., M. \& WEERAKKODY, V. (2009). CurrentT State of E-services in Saudi Arabia: The Case of Intermediaries in Facilitiing Government Services in Madinah City. European and Mediterranean Conference on Information Systems. Crown Plaza Hotel, Izmir.

ALTMAN, C. (2002). Converging Technologies: The Future of the Global Information Society. First Committee Chair Report to the UN General Assembly UNISCA.

ANDERSEN, K. V. \& HENRIKSEN, H. Z. (2005). The First Leg of E-Government Research: Domains and Application Areas 1998 - 2003. International Journal of Electronic Government Research, 1, 26 - 44.

APEC. (2000). e-Readiness Assessment Guid [Online]. Asia-Pacific Economic Cooperation. Available: http://www.apec.org/apec/ [Accessed 15 Sep. 2010].

APEC. (2008). e-Commerce Readiness Assessment Initiative. APEC.

AZAB, N. A., KAMEL, S. \& DAFOUlAS, G. (2009). A Suggested Framework for Assessing Electronic Government Readiness in Egypt. Electronic Journal of e-Government 7, 11 - 28.

BAARK, E. \& HEEKS, R. (1999). Donor-funded information technology transfer projects: evaluating the life-cycle approach in four Chinese science and technology projects. Information Technology for Development, 8, 185-197.

BAKRY, S. H. (2004). Development of e-Government: A STOPE view. International Journal of Network Management 14, 339-350

BALOGUN, J. \& HAILEY. (2004). Exploring Strategic change, London, Prentice Hall.

BAZERMAN, M. (2010). Announcing IACM 2010 23rd Annual Conference Abstracting eJournal Social Science Electronic Publishing, Inc. .

BECKER, S. A. \& NOWAK, L. L. (2003). Automated support for older adult accessibility of e-government web sites. Digital Government Society of North America, 130, 1-4.

BEHARA G., V., V. \& M., R. (2009). Service Oriented Architecture for E-Governance. BPTrends.

BELLAMY, C. \& TAYLOR, J. (1994). Introduction: Exploiting IT in Public Administration: Towards the Information Polity. Public Administration, 72, 1-12.

BLAIR, B. T. (2004). An Enterprise Content Management Primer. The Information Management Journal.

BRANNEN, A. (2001). E-Government in California: Providing Services to Citizens through the Internet. Journal of State Government, 74.

BRETSCHNEIDER, S., GANT, J. \& AHN, M. (2003). A General Model of E-Government service Adoption: Empirical Exploration. Public Management Research Conference. Washington, DC: Georgetown Public Policy Institute

BUI, T. X., SANKARAN, S. \& SEBASTIAN, I. M. (2003). A framework for measuring national e-readiness. International Journal Electronic Business, 1, 3-22.

CALDOW, J. (1991). The Quest for Electronic Government: A Defining Vision. The Institute for Electronic Government, IBM Corporation.

CARTER, L. \& BELANGER, F. (2005). The utilization of e-government services: citizen trust, innovation and acceptance factors. Information Systems Journal, 15, 5-25.

CENTER FOR INTERNATIONAL DEVELOPMENT - HARVARD UNIVERSITY AND IBM. (2007). Readiness for the Networked World: A Guide for Developing Countries. (CID) and IBM

CHAPPELL, D. A. (2004). Enterprise Service Bus, USA, O'Reilly Media, Inc.

CHEN, H. (2002). Issue Digital Government: technologies and practices. Decision Support Systems, 34, 223-227.

CHESHER, M., KAURA, R. \& AL., E. (2003). Electronic Business \& Commerce, London, Springer.

CID. (2002). Readiness for the Networked World: A Guide for Developing Countries. The GeoSinc Facilitation Center, The Harvard University Center for International Development.

CRIADO, J. I. \& RAMILO, M. C. (2003). E-Government in practice: an analysis of website orientation to citizens in Spanish municipalities. International Journal of Public Sector Management, 18, 191-218. 
EBRAHIM, Z. \& IRANI, Z. (2005). E-government adoption: Architecture and Barriers. Business Process Management Journal, 11, 589-611.

FORMAN, M. \& THOMPSON, D. (2007). National e-Government Portals [Online]. The e-Development Services Thematic Group is powered by GICT and ISG in collaboration with WBI. Available: http://www.worldbank.org/edevelopment [Accessed 10 Feb. 2011].

FOUNTAIN, J. (2001). Building the Virtual State: Information technology and institutional change. Brookings Institution Press.

GARCIA-MOLINA, H. \& POLYZOIS, C. A. (2002). In: Thirty-Fifth IEEE Computer Society International Conference, 2002 San Francisco, CA, USA.

GIL-GARCIA, J. R. \& PARDO, T. A. (2005). E-government success factors: Mapping practical tools to theoretical foundations. Government Information Quarterly.

HEEKS, R. (2003). Most eGovernment-for-Development Projects Fail: How Can Risks be Reduced? [Online]. Available: http://unpan1.un.org/intradoc/groups/public/documents/NISPAcee/UNPAN015488.pdf [Accessed Aug 28 2010].

HEEKS, R. (2005a). e-Government as a Carrier of Context. Journal of Public Policy, 25, 51-74.

HEEKS, R. (2005b). Implementing and Managing E-Government: An International Text. Sage Publishers.

HUANG, W., D'AMBRA, J. \& VIKRANT, B. (2002). Key Factors Influencing the Adoption of E-Government in Australian Public Sectors. 8th Americas Conference on Information Systems. Dallas, USA.

IBM. (2001). Creating an Infrastructure for eGovernment: Enabling Government Innovation [Online]. IBM public sector. [Accessed 28 Nov. 2010].

IBM. (2011). ICT Infrastructure [Online]. IBM. Available: www.ibm.com [Accessed 10 Feb. 2011].

IBM AND PTC. (2010). Enterprise Content Management: Challenges and Considerations XML Publisher Journal.

IDA. (2004). Multi-channel delivery of eGovernment services. Interchange of Data between Administrations

INJAZZ J. CHEN \& KAREN POPOVICH. (2003). Understanding customer relationship management (CRM): People, process and technology. Business Process Management Journal, 9, 672 - 688.

JANSEN, A. (2005). Assessing e-Government Progress - Why and What. University of Oslo: Department of e-Government Studies.

LAYNE, K. \& LEE, J. (2001). Developing fully functional E-government: A four stage model. Government Information Quarterly, 18, 122-136.

LEE, S. M., TAN, X. \& TRIMI, S. (2005). Current practices of leading e-government countries. Communications of the ACM, 84, 99-104.

LEE, Y. N. (2010). E-Government Application [Online]. UN-APCICT. Available: $<$ http://www.unapcict.org/academy> [Accessed 9 Nov 2010].

MACASIO, J. (2009a). ICT Services Management Practitioner's Not E-enterprise Architecture [Online]. Onecitizen. Available: www.onecitizen.net [Accessed 23 Sep 2010].

MACASIO, J. (2009b). Open Practitioner Notes: Information Systems Strategic Planning Basics [Online]. OneCitizen. Available: www.onecitizen.net [Accessed 17 Sep 2010].

MACIASZEK, L. A. (2004). International Conference on Enterprise Information Systems. Porto, Portugal

MAHESHWARI, B., VINOD KUMAR, UMA KUMAR \& SHARAN, V. (2009). E-Government Portal Effectiveness : Managerial Considerations for Design and Development. Computer Society of India.

MARTIN, B. \& BRYNE, T. (2003). Implementing e-Gov: widening the lens. The Electronic Journal of E-Government, 1, 11-22.

MEENA, R. S. (2009). Environmental-informatics---A solution for long term environmental research. Global Journal of Enterprise Information System, 1.

MICROSOFT. (2010). Microsoft Global e-governance Strategy [Online] Available: Microsoft Public Sector Group with United Nations, World Bank ; US Department of State Available: www.microsoft.com [Accessed]. 
MILLARD, J. (2007). European e-Government 2005-2007 [Online]. Available: $<$ http://www.epractice.eu/files/download/awards/ResearchReport2007.pdf $>$ [Accessed 10 Jan 2011].

MOODLEY, S. (2003). The challenge of e-business for the South African apparel sector. Technovation, 23, 557-70.

MOON, M. J. (2002). The evolution of e-government among municipalities: rhetoric or reality? Public Administration Review, 26, 424-434.

MUMICK I. S., QUASS D. \& S., M. B. (1997). Maintenance of Data Cubes and Summary Tables in a Warehouse. Conf. on Management Proc. ACM SIGMOD Int. .

NORRIS, D. F. \& LLOYD, B. A. (2006). The Scholarly Literature on E-Government: Characterising a Nascent Field. International Journal of Electronic Government Research, 2, 40 - 56.

NORRIS, D. F. \& MOON, M. J. (2005). Advancing E-Government at the Grassroots: Tortoise or Hare? . Public Administration Review, 65, 64-75.

O’NEILL, R. (2009). E-government: Transformation of Public Governanace in New Zealand? , Victoria University of Wellington.

OECD. (2002). E-Government Project: Key Issues and Findings, Public Governance and Territorial Development Directorate. Public Management Committee.

OECD. (2003). e-Government Studies: The E-Government Imperative. OECD Publishing.

ORACLE. (2010). Oracle portal [Online]. Oracle. Available: www.oracle.com [Accessed 8 Feb. 2011].

PAN, S.-L., TAN, C.-W. \& LIM, E. T. K. (2006). Customer relationship management (CRM) in e-government: a relational perspective. Decision Support Systems 42.

PATRIZIO, D. N., ISABELLA, M., ROCCA, G. L. \& VALENTINA, T. (2004). ICT Infrastructure - the Regional Dimension. Benchmarking the Information Society: e-Europe Indicators for European Regions. BISER.

PFLEEGER, C. P. \& PFLEEGER, S. L. (2003). Security in Computing, NJ, USA, Prentice Hall.

RAHMAN, H. 2007. E-Government Readiness: from the Design Table to the Grass Roots. ACM 978-1-59593-822-0/07/12.

RAMAKRISHNAN , R. \& J., G. (1999). Database Management System 2nd ISBN:0072322063.

RAMPERSAD, H. K. (2002). Total Performance Scorecard; een speurtocht naar zelfkennis en competentieontwikkeling van lerende organisaties, Scriptum Management, Schiedam.

REDDICK, C. G. (2005). Citizen Interaction with E-government: From the Streets to Servers? Government Information Quarterly, 22, 38-57.

RIFAI H. S., HENDRICKS L. A., KILBORN K. \& B., B. P. (2005). A Geographic Information System (GIS) User Interface for Delineating Wellhead Protection Areas. 31, 480-488.

RIZK, N. (2004). E-readiness assessment of small and medium enterprises in Egypt: A micro study [Online]. Cairo: American University. Available: <http://www.sba.luc.edu/orgs/meea/volume6/Rizk.htm> [Accessed 9 Jan 2011].

SAFAI-AMIN, M. (2002). Information technologies: challenges and opportunities for local governments. Journal of Government Information, 27, 471-479.

SAMTANI, G. \& SADHWANI, D. (2002). Web Services and Application Frameworks (.NET and J2EE), Tect Ltd.

SERES, A. (2010). Three Database Management Systems (DBMS) compared. Open Source Science Journal, 2, 65-82.

SHARIF, A. M., IRANI, Z. \& LOVE, P. E. D. (2005). Integrating ERP using EAI: a model for post hoc evaluation. European Journal of Information Systems 14 162-174

SHARIFI, H. \& ZAREI, B. (2004). An adaptive approach for implementing e-government I.R. Iran, Journal of Government Information, 30.

STARKEY.K., TEMPEST.S \& A, M. K. (2004). How Organizations Learn, Managing the Search for Knowledge. Second Edition, Thomson. 
STAUFFACHER, G. (2002). E-Government as and Instrument of Public Management Reform. In: 2ND (ed.) E-Government Conference.

STEPHEN, M., MUTULA \& PIETER, V. B. (2006). An evaluation of e-readiness assessment tools with respect to information access: Towards an integrated information rich tool. International Journal of Information Management 26, 212-223.

THEMISTOCLEOUS, M. \& IRANI, Z. E. A. (2002). Enterprise application integration: an emerging technology for integrating ERP and supply chains. European Conference on Information Systems. Gdansk.

THOMPSON, F. \& JONES, L. R. (2008). Reaping the Advantages of Information and Modern Technology: Moving from Bureaucracy to Hyperarchy and Netcentricity International Public Management Review 9 , 142 186

UNDPEPA/ASPA. (2002). Benchmarking e-government: A global perspective [Online]. UNDPEPA/ASPA. Available: http://www/unspan/org.egovernment/benchmarking\%20Egov\%202001.pdf. [Accessed 15 Jan. 2011 ].

WORLD BANK. (2005). E-Ready for What? E-Readiness in Developing Countries: Current Status and Prospects toward the Millennium Development Goals. In: PROGRAM, I. F. D. (ed.). USA.

WORLD BANK. (2006). Information and Communications for Development 2006: Global Trends and Policies. World Bank Publications.

YESSER. (2005). Supporting plans and methodologies: (a) E-Readiness assessment methodology for government organizations. Riyadh, Saudi Arabia: E-government Program, Ministry Communications and Information Technology (MCIT). 
Table 1. Business and IS Dimension - Applications and systems

\begin{tabular}{|c|c|c|}
\hline Application/Systems & Description & References \\
\hline $\begin{array}{l}\text { Core Business } \\
\text { Applications }\end{array}$ & $\begin{array}{l}\text { Applications that are specifically used by one } \\
\text { government organization. }\end{array}$ & (Yesser 2005) \\
\hline $\begin{array}{l}\text { Enterprise Resource } \\
\text { Planning (ERP) }\end{array}$ & $\begin{array}{l}\text { Integrated and draw directly from live databases } \\
\text { linked to the systems such as HR, Payroll, } \\
\text { Finance, Procurement, etc.. }\end{array}$ & $\begin{array}{l}\text { (Sharif et al., 2005, } \\
\text { Yesser, 2005) }\end{array}$ \\
\hline $\begin{array}{l}\text { Enterprise Application } \\
\text { Integration (EAI) }\end{array}$ & $\begin{array}{l}\text { Systems have emerged to overcome some of the } \\
\text { limitations of ERP, through facilitating integration } \\
\text { through the use of technologies that allow } \\
\text { corporate IS subsystems to communicate with one } \\
\text { another. } \\
\text { In the context of using enterprise technologies to } \\
\text { integrate ERP with other organizational business } \\
\text { systems (because ERP systems is a difficult, } \\
\text { costly, and risky). }\end{array}$ & $\begin{array}{l}\text { (Themistocleous and } \\
\text { Irani, 2002) }\end{array}$ \\
\hline Web services & $\begin{array}{l}\text { Standards-based and suited to build common } \\
\text { infrastructure to reduce the barriers of business } \\
\text { integrations, hence, enable e-government systems } \\
\text { to collaborate with each other regardless of } \\
\text { underlying infrastructure. }\end{array}$ & $\begin{array}{l}\text { (Samtani and Sadhwani, } \\
\text { 2002, Huang et al., } \\
\text { 2002) }\end{array}$ \\
\hline $\begin{array}{l}\text { Electronic Data } \\
\text { Interchange (EDI) }\end{array}$ & $\begin{array}{l}\text { Designed to exchange documents between } \\
\text { organizations. }\end{array}$ & $\begin{array}{l}\text { (Meena, 2009, Chesher } \\
\text { et al., 2003) }\end{array}$ \\
\hline $\begin{array}{l}\text { Customer Relationship } \\
\text { Management (CRM) }\end{array}$ & $\begin{array}{l}\text { An integrated approach to managing relationships } \\
\text { by focusing on customer retention and } \\
\text { relationship development. } \\
\text { CRM has evolved from advances in information } \\
\text { technology and organizational change in } \\
\text { customer-centric processes. }\end{array}$ & $\begin{array}{l}\text { (Injazz J. Chen and } \\
\text { Karen Popovich, 2003) } \\
\text { (Pan et al., 2006) }\end{array}$ \\
\hline $\begin{array}{l}\text { Geographic } \\
\text { Information Systems } \\
\text { (GIS) }\end{array}$ & $\begin{array}{l}\text { A digital tool to help in the storing, analysis, } \\
\text { mapping, and illustration of large amounts of } \\
\text { diverse electronic data. }\end{array}$ & (Rifai H. S. et al., 2005) \\
\hline $\begin{array}{l}\text { Enterprise Content } \\
\text { Management (ECM) }\end{array}$ & $\begin{array}{l}\text { The technologies, tools, and methods used to } \\
\text { capture, manage, store, preserve, and deliver } \\
\text { content across an enterprise. } \\
\text { This is a broad definition that covers a wide range } \\
\text { of technological categories such as Electronic } \\
\text { Document Management (EDM), Business Process } \\
\text { Management (BPM) and business process. }\end{array}$ & (IBM and PTC, 2010) \\
\hline $\begin{array}{l}\text { Database Management } \\
\text { System (DBMS) }\end{array}$ & $\begin{array}{l}\text { A necessity for any course in database systems or } \\
\text { file organization. DBMS offers "a hands-on } \\
\text { approach" to relational database systems, with a } \\
\text { highlighting on practical topics such as indexing } \\
\text { methods, SQL, and database design. }\end{array}$ & $\begin{array}{l}\text { (Ramakrishnan and J., } \\
\text { 1999, Seres, 2010) }\end{array}$ \\
\hline Data Warehousing & $\begin{array}{l}\text { A collection of data from multiple sources, } \\
\text { integrated into a data store and widened by outline } \\
\text { information such as aggregate views. }\end{array}$ & $\begin{array}{l}\text { (Bazerman, 2010) } \\
\text { (Mumick I. S. et al., } \\
\text { 1997) }\end{array}$ \\
\hline
\end{tabular}




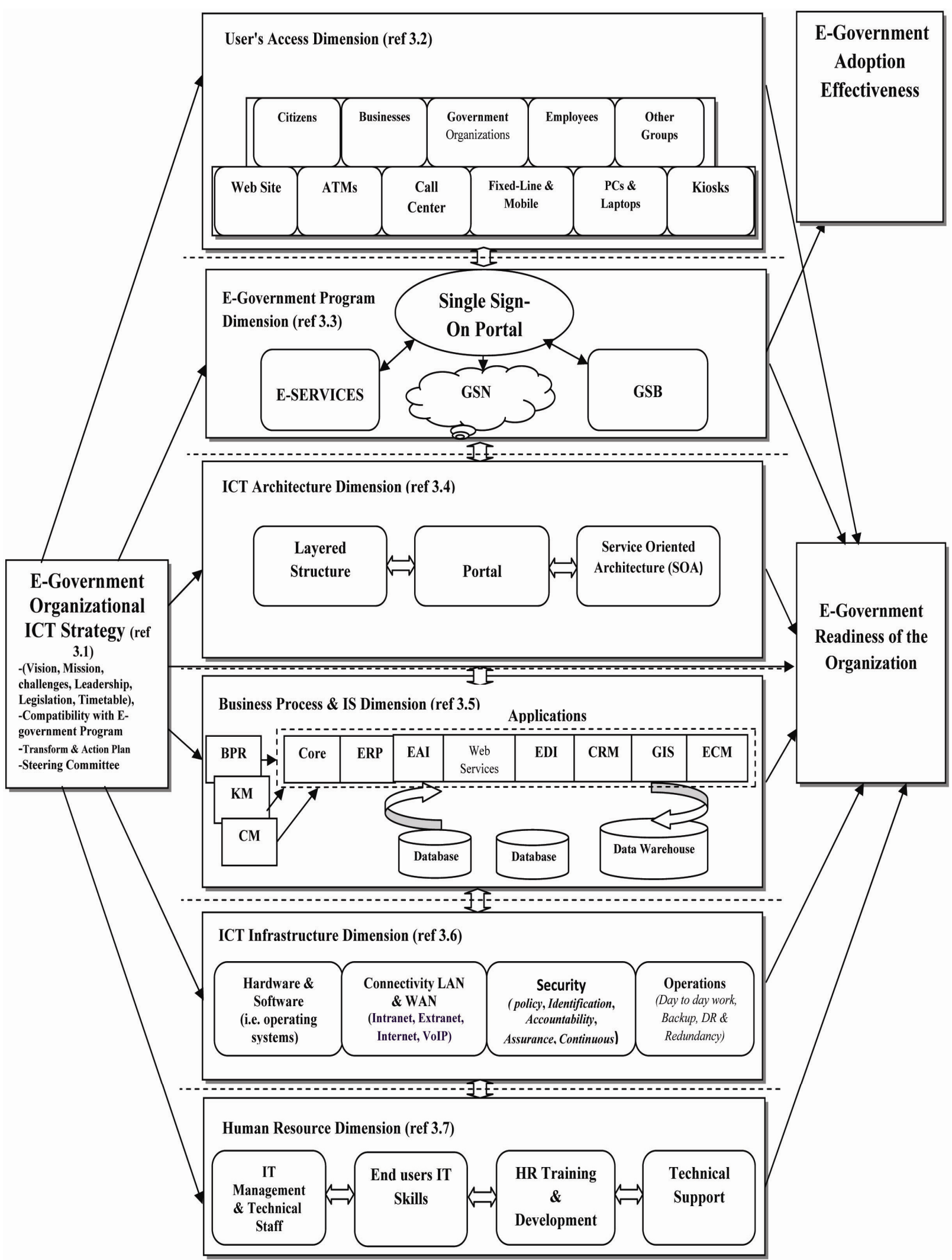

Figure 1. E-government framework for assessing organizational ICT readiness in Developing Countries 